\title{
Reflection on practice: an exploration of a virtual online collaboration as preparation for the year abroad
}

\author{
Claire $0^{\prime}$ Reilly $^{1}$
}

\section{Abstract}

his paper describes an exploratory online intercultural exchange that took place between two universities, one in Ireland and the other in Germany. Students

L worked together virtually - across cultures and disciplines - on a project-based task for assessment. Based on an analysis of the reflective learning journals submitted over the course of the semester, there is evidence that a virtual online learning environment may be considered as an effective way of preparing students for a Year Abroad (YA), triggering a path of reflection and (inter-) cultural learning. From insights gained doing this Virtual Exchange (VE), a type of inventory for virtual online collaboration is suggested, which may serve as a task-checklist for future VEs.

\section{Keywords: pre-mobility preparatory courses; virtual exchange; task-checklist for virtual online (project) collaboration.}

\section{Introduction}

Online intercultural exchange, or telecollaboration, most recently known as VE (O’Dowd \& O'Rourke, 2019, p. 2), involves internet-mediated intercultural engagement between classes in geographically distant locations (cf. Guth, Helm, \& O'Dowd, 2012). After more than 20 years in existence, VE is recognised as a convincing way of pursuing various pedagogical goals in the classroom, such as

1. University College Cork, Ireland; claire.oreilly@ucc.ie; https://orcid.org/0000-0003-3010-5703

How to cite this article: O'Reilly, C. (2021). Reflection on practice: an exploration of a virtual online collaboration as preparation for the year abroad. Journal of Virtual Exchange, 4, 50-61. https://doi.org/10.21827/jve.4.35781 
fostering intercultural competence (Lenkaitis, Calo, \& Venegas Escobar, 2019), developing a global mindset (Patterson, Carrillo, \& Salinas, 2012), and still, largely, as a forum for language exchange and as a vehicle for enhancing language proficiency skills (see O’Dowd \& O’Rourke, 2019).

An area of emerging interest in VE has been its value as a pre-mobility endeavour to prepare students for a stay abroad (e.g. see Lee \& Song, 2019), and even as a replacement for the YA itself (Hilliker, 2020).

In this paper, a VE between University College Cork and Cologne University of Applied Sciences will be described and the main findings discussed. The collaboration was part of the pre-mobility preparation for the Irish students' YA in Germany. The hope was that working with native informants in the host culture - together with guided reflection in class - would help trigger a process of deeper intercultural learning over and above the engagement with concepts in a textbook, and therefore be an effective way to prepare the students for going abroad. Such a collaboration speaks directly to best practise for the preparation of the YA in that it intentionally structures opportunities for cross-cultural interaction and active exploration of the host country, while providing students with opportunities for reflective learning (as advocated by Engbert \& Jourian, 2015).

This paper will first set out the context of the exchange, highlight the objectives, and expand on the project design before discussing the evaluation and outcomes drawing from students' self-reports in reflective learning journals. It will finish with a conclusion and reflect on obstacles and challenges. Finally, in consideration of implications, a planning grid or inventory is suggested (Appendix II) which will help serve as an orientation and discussion tool for similar virtual projects.

\section{Context}

For the German students at Cologne University of Applied Sciences, the VE was part of a module on intercultural teamwork (Interkulturelle Teamkompetenz) providing engineering and computer science students both theoretical input on developing intercultural competence, and the opportunity to work first-hand on a virtual project across cultures. The goal thereby was that students would develop self-reflective and behavioural competencies inherent in the concept of intercultural competence (following Thomas, 2003).

This was a hybrid course with formal synchronous inputs from educators addressing both groups simultaneously (via Adobe Connect or Skype), and with informal aspects as students organised meetings virtually in their own time. Four thematic areas relevant to study abroad were introduced 
in German or in English. They comprised: intercultural learning and Intercultural Communication (ICC); living and studying abroad; digital skills in the humanities; and intercultural (team) competence.

A total of 32 students took part in the study: seventeen Irish students pursuing arts and commerce degrees, all in the first semester of their second year², and 15 German students from computer science and engineering faculties. The students were therefore working both interculturally and across their familiar subject disciplines in this VE.

\section{Objectives}

A number of learning objectives were envisaged with this VE including addressing fears associated with going abroad and increasing self-confidence. These aspects are inherent in intercultural learning and are closely aligned to the development of intercultural competence (cf. Bolten, 2006; Brislin, Landis, \& Brandt, 1983; Gersten, 1990) itself, understood here as promoting the below.

- Cognitive learning -> entails knowledge of ICC concepts

By imparting knowledge of concepts such as culture, living, and studying abroad, and teamwork (competence), cognitive learning was envisaged. Knowledge of these concepts was to help students understand how culture influences all human beings in various contexts.

- Affective learning -> refers to an appropriate emotional/relational engagement in the communication process

By placing students in authentic ICC settings, it was hoped they would develop positive outlooks in relation to the host culture including increased confidence in themselves (Selbstvertrauen) and learning motivation (interkulturelle Lernbereitschaft).

- Actions/behavioural -> displays appropriate and effective behaviours socially

Based on the knowledge received and the experiences derived from the project interaction, students would develop their communicative abilities and social skills, as well as increased trust in their German peers.

2. All the Irish students who took part in the module subsequently went abroad as planned in Year 3 . 
It was also envisaged that through practice, students' language skills would be enhanced. They were encouraged to speak German; however, it was left to them how much German to use and when (levels were typically between a B1 and B2).

Witte's (2011) conceptualisation of intercultural competence was a guiding belief of the Irish VE, in that ICC

"must be actively acquired by the learner, i.e. s/he must be inherently prepared to invest time and effort into the holistic process of learning, due to experiences of personal deficits in this regard. [...] The process of learning and acquiring intercultural competence must combine elements of intercultural experience and an acute awareness of the differences and similarities of the cultural constructs, norms, categories and beliefs involved” (p. 102, emphasis added).

\section{Project design}

The author has designed courses to prepare students for the international year of their degree (Year 3) in Germany for the past 15 years. The preparation integrates YA research, ICC, and cultural psychology. The aim is to help students develop skills and attitudes conducive to multiple learning outcomes (linguistic, cultural, and intercultural among others), and to equip them with conceptual tools to draw on in order to frame their cultural and intercultural experiences when abroad (cf. Kinast, 2000). The University College Cork-Cologne University of Applied Sciences module was a departure from the didactic lecturer-centred approach, and a first experience for both the author and the Irish students working virtually with German peers in an applied YA context.

The module ran for one semester (12 weeks) with two classroom hours per week. The collaboration from its inception to the finish spanned one year in all and culminated in an educational visit by the German students to the Irish university, where the digital projects were launched in a formal setting with a parchment ceremony ${ }^{3}$ (see Appendix 1). Working in bi-/cross-cultural teams, students' projects followed the theme Living in Cork / Living in Cologne and had to be submitted as one project in WordPress or Blog format (35 Marks).

Further assessment comprised reflective journals: Reflective Journal I (RJ I) set questions that had to do with students formulating their YA goals considering the research presented in class. In RJ II,

3. I would like to acknowledge Professor John O'Halloran, the then Vice-President of Teaching and Learning in University College Cork, who facilitated the award ceremony and made the event a very memorable one for the students. 
students had to consider the content of this course, and how their YA goals were impacted over the course of the module including an action strategy for achieving these goals (both 50 marks). In the third and final journal (RJ III), students reflected on their overall learning based on the interpretative triangle which includes personal learning, situational learning, and (inter-) cultural learning (15 marks). In all, there were over 90 pages of reflective learning journals submitted from all students, and they form the basis for this paper.

\section{Evaluation and discussion of outcomes}

The method chosen for the analysis of the journals was grounded theory, which involves the "use of an intensive, open-ended, and iterative process that simultaneously involves data collection, coding (data analysis), and memo-writing (theory building)" (Groat \& Wang, 2002, p. 181). The grounded theory approach, which was developed by Glaser and Strauss (1967), requires the researcher to develop common or contradictory themes and patterns from the data which can be used as a basis for interpretation (Easterby-Smith, Thorpe, \& Lowe, 1991, p. 105). This process necessitated the reading and re-reading of the journal entries using coding and category-building. As data are categorised and interconnections made, theories emerge and can then later be tested. The main categories in the RJs related to: teamwork, language and cultural awareness, and YA (goals).

According to Patton (1990), “direct quotations can help to reveal the respondents' levels of emotion, the way in which they have organised their worlds, their thoughts about what is happening, their experiences, and their basic perceptions” (p. 24, cited in Linehan, 1998, p. 202). Recognising the value of quotations, sample excerpts from the learning journals are given below. Any references to students' names have been changed to protect anonymity, and the annotation follows the format male/female, number, and journal entry.

\subsection{Teamwork}

Insights from doing intercultural teamwork ranged from how to set about doing a project at the very outset, such as how often to meet and the choice of digital forums to meet, for example,

"I noticed that we all had different preferences when it came to communication methods. The German teams seemed to prefer the messaging application WhatsApp to stay in touch, while the Irish preferred Facebook. In order to communicate effectively, compromises had to be made" (F/15, RJ III), 
to the very communication within the project itself:

"I noticed a difference in the way the Irish and Germans communicated for the first time over an initial Skype conversation between the four of us where we discussed ideas for our project. While [A.] and I listened and noted what the Germans thoughts and ideas were and responded in a positive way, I felt [Y.] in particular, was quick to shoot down some of our original ideas for the project. At first if I am being honest, I took this as rudeness and attributed it to his personality, however after several more Skype conversations, it quickly became very clear that he meant no disrespect to us, and that his honesty was not a slight at our expense. While it could be argued that [J.] was more positive throughout the duration of our project, it is also true that I feel [Y.] was more involved in decisions and perhaps cared more about the overall quality of the project itself” (M/17, RJ II).

Here we note a shift in views over the course of the project: what the student initially thought was rudeness on the part of his German partner, turned into a realisation that 'no disrespect' was meant and that his peer's active involvement meant that he 'cared' about the project. This realisation was only possible over time where the initial impressions could be revised and revisited.

Surmounting the many and little project challenges along the way meant a great deal of personal satisfaction when the project was completed as it helped develop a sense of cohesion and group achievement, for example:

"participating in the project itself was something that I genuinely enjoyed [...]. I thoroughly enjoyed the ideas and decision-making process as it not only involved our group coming together to start and complete the project, but also working in this group-setting the way that we did allowed me to get to know my fellow group members, and it is this aspect of the project in particular that appealed to me the most. I can honestly say that I made friends and enjoyed myself throughout the whole process” (F/3, RJ II).

Thus Finding (or Theory) 1: VE offers a worthwhile forum for meaningful teamwork and relationship-building among students.

\subsection{Language and cultural awareness}

Second, it was in this interaction that students had to negotiate the language and the medium of communication. Rather than clear language advancements, students realised that their language skills were not at the same level as their German peers, and some did not feel confident to proceed 
in German. Others reported that they had to employ negotiation skills to use the Foreign Language (FL). It came as a surprise that the German students so readily talked in English, clearly enjoying the opportunity to practise their FL skills.

"On one occasion my partner and I started a conversation in German, but the German boys still chose to answer back in English. Perhaps they felt as though they had a better level of English than we did of German?” (F/4, RJ I and II).

"The willingness of both [M.] and [A.] to communicate using a second language was immediately noticeable, and they did so with enthusiasm, as if they genuinely regarded this as an opportunity to practise their oral English skills. Although in one sense this was great, perhaps their disregard for our ambition to practise our spoken German can be seen as a rather one-sided relationship which I believe to be an intercultural barrier, and is something which I am now quite wary of [...]. I cannot help but feel that perhaps the commonly shared Irish mentality of being in a sense 'laid back' or non-confrontational hindered our opportunity for our Skype conversations to be more than they were, while the German's honesty and intensity toward the project and their use of English overpowered us to an extent” (M/17, RJ II).

Here this student reflects on how perceptions of cultural belonging ('Irish mentality') affected communication and the ensuing interaction. This coupled with stronger FL skills on the German side left him feeling "overpowered". Also, other students commented that this fact meant that they let go of the expectation of speaking German altogether.

"We communicated mainly through English as the Germans standard of English was much better than our standard of German and we wanted to avoid confusion so communicating through English was the most effective way of speaking” (F/3, RJ II).

As students reflected on the views their German partners had of the language opportunity, self- and other-perceptions, or auto-images and hetero-images, were indirectly addressed and challenged. This echoes Kinginger's finding that “ $\mathrm{a}[\mathrm{n}]$ advantage of telecollaboration can be exposure to ideologies students may encounter abroad, including negotiation of attitudes and stereotypes about foreigner identities” (Kinginger, 2016, p. 27).

So, Finding 2: VE is a worthwhile platform for learning directly about cultural negotiation and indirectly about the self. The process of (re-)negotiation served as a springboard for cultural self-appraisal. 


\subsection{YA (goals)}

A third main finding concerned insights gained into future learning related to the YA, which this quote illustrates:

"honestly, before this module I only had a whole list of goals and aims for the YA, but not a single strategy on how to achieve them. In the past three weeks, my focus has shifted from what I want to do, to how I want to do these things. It is a great thing that I have started thinking of this now, rather than a few weeks before I move to Germany!” (F/2, RJ I).

The realisation of difference in FL skills meant that a repeated observation was to work on the language and with this a plan to use the time abroad for language proficiency, e.g.

"I have decided to take matters into my own hands and to learn to become fluent by myself. I will befriend German students and another important goal for me is to get a part-time job for the year" (F/4, RJ I and II).

Another common YA insight was the reference to the direct experience of sitting in on German lectures and being 'live' in a German academic setting. Here, the immediacy to German peers revealed importance attached to formality (and informality):

"I did pick up on cultural differences over the course of the project - the German side were more formal towards their lecturers then [sic] us Irish. The Irish side were shyer than the Germans when it came to talk [sic] in front of the class - not due to lack of knowledge, it is just a cultural thing” (F/2, RJ III).

"I have learned a great deal about how university life may differ between Ireland and Germany [...]. In Ireland, a lot of the time you are on a first name basis with your lecturers, while in Germany this would be exceptionally rare” (F/3, RJ II).

Notably, the synchronous German-Irish lectures helped address fears and questions associated with completing an academic curriculum in a foreign country, as

"[b]eing able to listen to a full German lecture was of great benefit [in my opinion] as it got rid of all anxiety about the way lectures would be conducted next year to some extent” (M/14, RJ II). 
Finding 3: a VE is a useful pedagogical tool to help students define their individual YA goals both within and outside of the university setting, and to decrease fears associated with going abroad.

Taking all RJs into consideration, by the end of the semester, students were noticeably positive about going abroad and related feeling more confident as to any challenges they might encounter. This last quote summarises a clear transition over the course of the module:

"I have come to realise that I may have been a little naïve in my initial perceptions with regards to Erasmus. Because I am so excited for the YA, I presumed that when I landed in Germany, everything would be fantastic, and I would have no issues whatsoever in adapting to the rather small culture difference between Ireland and Germany. However, while the culture difference between our two countries may be relatively miniscule as opposed to Ireland and India, for example, I now recognise that there are significant changes I should prepare myselffor dealing with. Therefore, this module has been extremely worthwhile to me as I now feel more equipped to deal with the various cultural diversities I am certain to encounter while abroad” (F/3, RJ II).

To conclude: navigating the project successfully brought with it a more realistic view of what intercultural encounters entail for the students, and in the latter case a sense of being 'more equipped' to deal with cultural diversity during the YA.

\section{Conclusions and implications}

The aim of this module was to explore if, in a departure to traditional formats, VE could be regarded as an effective way of preparing students for going abroad based on an analysis of reflective learning journals submitted over the semester. While the aim was not to set out to statistically quantify if intercultural competence was being achieved, the grounded theory approach showed evidence of the dimensions of ICC in the learning journals. Cognitively, students gained knowledge relating to living and studying abroad, and first-hand knowledge about culture difference in the experience of doing the project; affective learning took place as students related increased motivation ("I now recognise that there are significant changes I should prepare myself for") and decreasing fear associated with going abroad. As the learning journals progressed, later entries showed more intentional learners and more confidence regarding social interaction with peers which relates to the action-behavioural dimension inherent in ICC. 
Particularly evident in the reading of the learning journals was that it was in the interaction with the students, away from formal learning structures, that cultural learning took place and critical reflection and questioning occurred. Being immersed in real-life situations meant students had to negotiate meaning with German peers and this provided a rich path of learning of self and other. It is this dynamic that Kinginger (2016) underlines as one of the advantages of online exchanges: "in telecollaborative pedagogies, students can create social connections with their peers, see themselves through the eyes of others, [and] be exposed to specific attitudes” (p. 20).

In sum, learning happened, as one might expect in an interdisciplinary and intercultural project, on multiple levels: in addition to the gains made from the doing of intercultural team projects, learning about language negotiation and cultural (self-) awareness, students reported clarity as to their purpose associated with the YA - this stemmed from the work on goals and self-regulation strategies as a core part of navigating the YA.

Despite notable learning gains, there were challenges and obstacles that formed part of the overall learning experience. Additional preparation and time for the VE was necessary over and above a comparable five credit module. Challenges in technology proved to be an obstacle to the project, and on more than one occasion because of the inability to connect or a poor connection, the live streaming had to be abandoned. However, an online educational learning repository proved useful as slides and course-notes were made available for students to download after class. Semesters were misaligned with different starting dates, and the time-difference affected students scheduling meetings (cf. Lee \& Markey, 2014, p. 282).

Looking forward, and based on learning from this VE, a checklist is included for virtual project collaboration which features some of the key decisions that had to be made in this project, from funding to digital collaborative tools, to thoughts on reflection and evaluation of the collaboration (Appendix II). As an overview table, this may help serve as a basis for elaboration and further work in the future.

Notwithstanding the challenges, the VE initiated a learning path that will presumably outlive the course itself: as students were given an opportunity to collaborate with German students in advance of the YA, the findings, though limited in terms of their general application due to the specific subject-focus and scope, point to cognitive, affective and behavioural learning outcomes inherent in developing intercultural competence, including increasing motivation and decreasing fears about going abroad. Hence the VE does indeed point to best practise in YA preparation, as envisaged by Engbert and Jourian (2015) as the interaction enabled active exploration of the host country, the 
university environment and much more ${ }^{4}$. In closing, the final words will belong to a participating student:

"throughout the course of the module we were given the unique opportunity to learn from other students in Germany. I thoroughly enjoyed the experience [...] and felt that it was an excellent way to learn first-hand information about the German culture” (F/1, RJ III).

\section{Acknowledgements}

I would like to thank the two anonymous reviewers for their comments and suggestions on an earlier version of this paper.

The VE was established with Cologne University of Applied Sciences based on personal contacts made at the University of Regensburg. Many thanks are due to the project partners, especially to Dr Gertrude Cotter (University College Cork), who approached the author regarding the project idea at the outset, and to Prof Siegfried Stumpf and Stefanie Gruttauer (Psychologist/Lecturer), Cologne University of Applied Sciences. I would like to acknowledge in particular the role of Dr Cotter as she provided a significant contribution in designing and implementing this VE. The collaboration was funded by a local authority grant (Cork City Council) following an open-round of calls for projects which link the twinned cities of Cork and Cologne and their citizens.

\section{References}

Bolten, J. (2006). Interkultureller Trainingsbedarf aus der Perspektive der Problemerfahrungen entsandter Führungskräfte. In K. Götz (Ed.), Interkulturelles Lernen. Interkulturelles Training (pp. 57-76). Mering.

Brislin, R. W., Landis, D., \& Brandt, M. (1983). Conceptualisations of intercultural behaviour and training. In D. Landis

\& R. Brislin (Eds), Handbook of intercultural training (pp. 1-35). Pergamon Press.

Easterby-Smith, M., Thorpe, R., \& Lowe, A. (1991). Management research. Sage.

Engbert, M., \& Jourian, T. J. (2015). Intercultural wonderment and study abroad. Frontiers: The International Journal of Study Abroad, 15(Spring), 1-19.

Gersten, M. C. (1990). Intercultural competence and expatriates. International Journal of Human Resource Management, 1(3), 241-262.

Glaser, B., \& Strauss, A. (1967). The discovery of grounded theory. Aldine de Gruyter.

4. The analysis of the VE described in this paper has helped to inform improvements to a similar virtual collaboration running this semester with the University of Applied Sciences Dresden. In this exchange, students are learning about narrative inquiry and life-writing working with German peers. 
Groat, L., \& Wang, D. (2002). Architectural research methods. Wiley \& Sons.

Guth, S., Helm F., \& O’Dowd, R. (2012). University language classes collaborating online. A report on the integration of telecollaborative networks in European universities. http://intent-project.eu

Hilliker, S. (2020). Virtual exchange as a study abroad alternative to foster language and culture exchange. TESOL Teacher Education, 23(4), 1-13.

Kinast, E. U. (2000). Evaluation interkultureller Trainings. Pabst.

Kinginger, C. (2016). Telecollaboration and student mobility for language learning. In S. Jager, M. Kurek, \& B. O’Rourke (Eds), New directions in telecollaborative research and practice: selected papers from the Second conference on telecollaboration in higher education (pp. 19-29). Research-publishing.net. https://doi.org/10.14705/rpnet.2016. telecollab2016.487

Lee, L., \& Markey, A. (2014). A study of learners' perceptions of online intercultural exchange through Web 2.0 technologies. ReCALL, 26(3), 281-297.

Lee, J., \& Song, J. (2019). Developing intercultural competence through study abroad, telecollaboration, and on-campus language study. Language Learning \& Technology, 23(3), 178-198. http://hdl.handle.net/10125/44702

Lenkaitis, C. A., Calo, S., \& Venegas Escobar, S. (2019). Exploring the intersection of language and culture via telecollaboration: utilizing videoconferencing for intercultural competence development. International Multilingual Research Journal, 13(2), 102-115.

Linehan, M. (1998). The senior female international managerial career move: a qualitative study in a European context. PhD Thesis. University College Cork. https://cora.ucc.ie/bitstream/handle/10468/802/LinehanM_PhD1998.pdf

O’Dowd, R., \& O'Rourke, B. (2019). New developments in virtual exchange in foreign language education. Language Learning \& Technology, 23(3), 1-7.

Patterson, L., Carrillo, P. B., \& Salinas, R. S. (2012). Lessons from a global learning virtual classroom. Journal of Studies in International Education, 16(2), 182-197.

Patton, M. (1990). Qualitative evaluation and research methods. Sage.

Thomas, A. (2003). Psychologie Interkulturellen Handelns. Hogrefe.

Witte, A. (2011). On the teachability and learnability of intercultural competence: developing facets of the 'inter'. In A. Witte \& T. Harden (Eds), Intercultural competence: concepts, challenges, evaluation (pp. 89-107). Peter Lang. 


\section{Virtual Exchange?}

Published by University of Groningen Press | UGP, a not-for-profit press

Groningen, The Netherlands | UGP@rug.nl

(C) 2021 UNICollaboration (collective work)

(C) 2021 by Authors (individual work)

Journal of Virtual Exchange 2021

Edited by Carolin Fuchs and Müge Satar

Publication date: 2021/05/24

Journal of Virtual Exchange (JVE) is an online, open-access, peer-reviewed journal aimed at practitioners and researchers in the field known variously as virtual exchange, telecollaboration, or online intercultural exchange. It is the official journal of UNICollaboration (https://www.UNICollaboration.org/), the international academic organisation dedicated to supporting and promoting telecollaboration and virtual exchange in higher-level education.

Rights. The whole volume is published under the Attribution-NonCommercial-NoDerivatives 4.0 International licence (CC BY-NCND 4.0); individual articles may have a different licence. Under the CC BY-NC-ND licence, the volume is freely available online for anybody to read, download, copy, and redistribute provided that the author(s), editorial team, and publisher are properly cited. Commercial use and derivative works are, however, not permitted.

Disclaimer. University of Groningen Press does not take any responsibility for the content of the pages written by the authors of this article. The authors have recognised that the work described was not published before, or that it was not under consideration for publication elsewhere. While the information in this article is believed to be true and accurate on the date of its going to press, neither UniCollaboration nor University of Groningen Press can accept any legal responsibility for any errors or omissions. Additionally, the publisher makes no warranty, expressed or implied, with respect to the material contained herein. While University of Groningen Press is committed to publishing works of integrity, the words are the authors' alone.

Trademark notice. Product or corporate names may be trademarks or registered trademarks, and are used only for identification and explanation without intent to infringe.

Copyrighted material. Every effort has been made by the editorial team to trace copyright holders and to obtain their permission for the use of copyrighted material in this article. In the event of errors or omissions, please notify the publisher of any corrections that will need to by incorporated in future editions of this article.

Typeset by Research-publishing.net (https://research-publishing.net)

Noto fonts are open source. All Noto fonts are published under the SIL Open Font License, Version 1.1. Noto is a trademark of Google Inc. (https://www.google.com/get/noto/).

ISSN: 2647-4832 (online only)

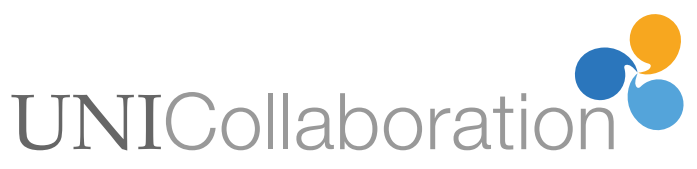




\begin{tabular}{|c|c|c|}
\hline Appendix I: & \multicolumn{2}{|c|}{ Project Overview 2015-2016 } \\
\hline Stages & Timeframe & Details \\
\hline \multirow{5}{*}{ I } & & \\
\hline & February & Discussion of Project / Proposal to German Partners in Cologne \\
\hline & & Town Twinning Grant Application submitted \\
\hline & May & Project and Grant Approval \\
\hline & $\begin{array}{l}\text { May- } \\
\text { September }\end{array}$ & $\begin{array}{l}\text { Course Design [identification of thematic areas / discussion } \\
\text { with university partners] }\end{array}$ \\
\hline $\begin{array}{l}\text { II } \\
\text { Implementation }\end{array}$ & September & $\begin{array}{l}\text { Delivery of course content }-4 \text { thematic strands: } \\
\text { Intercultural learning and intercultural communication } \\
\text { (O'Reilly and Cotter) } \\
\text { Living and studying abroad (Stumpf) } \\
\text { Digital skills in the humanities (Cotter) } \\
\text { Working in bi- and multi-cultural teams (Gruttauer) }\end{array}$ \\
\hline \multirow{3}{*}{$\begin{array}{l}\text { III } \\
\text { Evaluation and } \\
\text { Follow-up }\end{array}$} & $\begin{array}{l}\text { December- } \\
\text { January }\end{array}$ & $\begin{array}{l}\text { Post-course assessment of projects and self-reflective } \\
\text { component }\end{array}$ \\
\hline & February & $\begin{array}{l}\text { Cologne students' excursion to Cork } \\
\text { Launch of digital projects and award ceremony in UCC }\end{array}$ \\
\hline & $\begin{array}{l}\text { February- } \\
\text { March }\end{array}$ & $\begin{array}{l}\text { Budget administration and report to funding partners (City } \\
\text { Council) }\end{array}$ \\
\hline
\end{tabular}




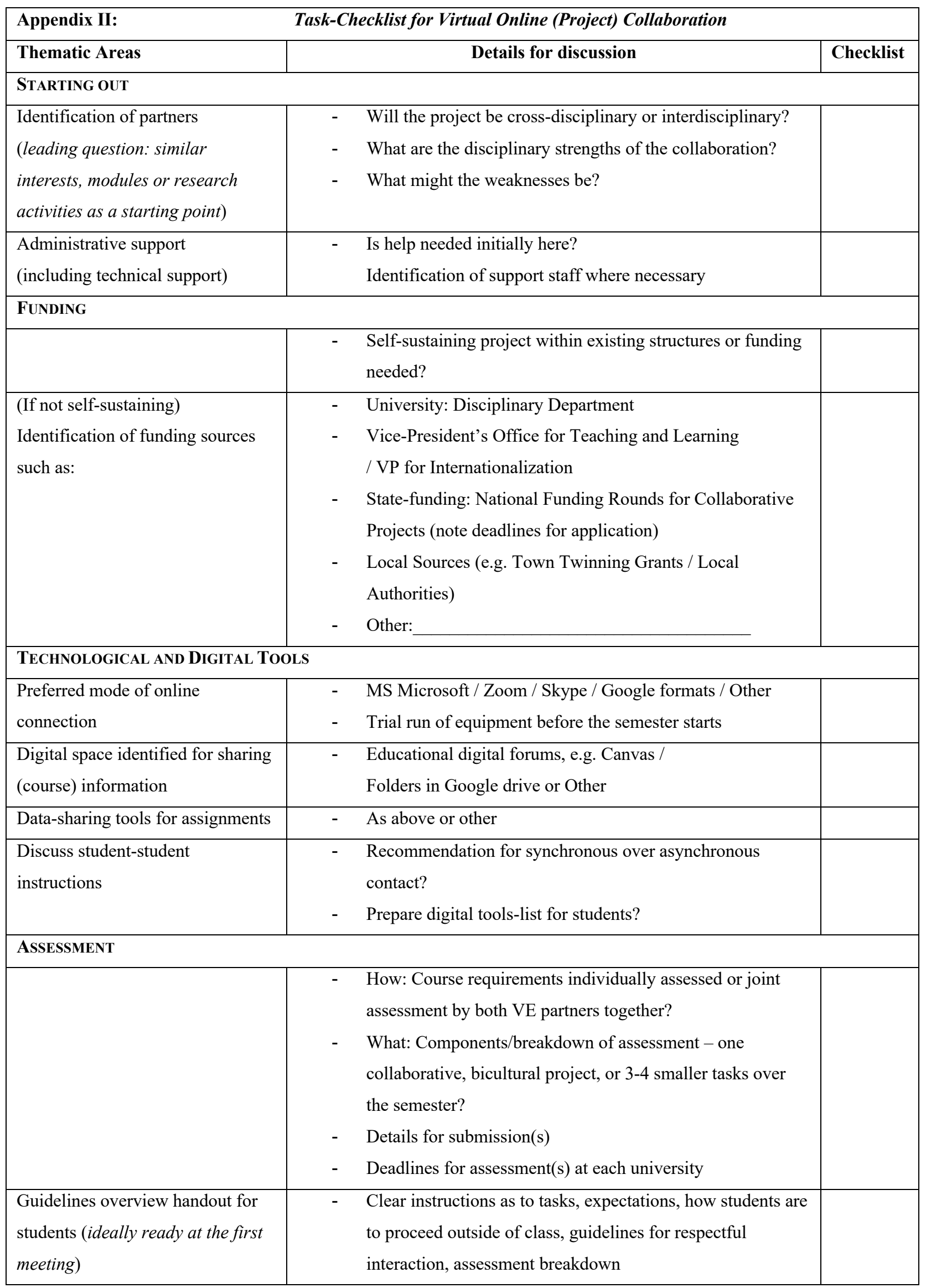




\begin{tabular}{|c|c|}
\hline & $\begin{array}{l}\text { - Upload guidelines overview handout onto digital class space } \\
\text { (in two languages if necessary) }\end{array}$ \\
\hline $\begin{array}{l}\text { Grading metrics } \\
\text { (often different) }\end{array}$ & $\begin{array}{l}\text { - Discussion of system of grading and agreement on approach } \\
\text { - If joint project: Discussion of correction of assessments and } \\
\text { criteria checklist of grading markers }\end{array}$ \\
\hline \multicolumn{2}{|l|}{ LANGUAGE COMPONENT } \\
\hline & $\begin{array}{ll} & \text { Discussion of language aspects (if any) } \\
\text { - } & \text { Main language(s) of instruction: } \\
\text { - } & \text { If more than one language: Aspects for integration of } \\
\text { language component (discussion of what, how, where, } \\
\text { when) }\end{array}$ \\
\hline \multicolumn{2}{|l|}{ ORGANIZATION } \\
\hline Semester dates & $\begin{array}{l}\text { - If semesters run asymmetrically a run-in period needs to be } \\
\text { covered with discussion of concepts }\end{array}$ \\
\hline Date and time & $\begin{array}{ll}\text { - } & \text { Time difference to be considered if relevant } \\
\text { - } & \text { Timetabling issues } \\
\text { - } & \text { Suitability of venue (basements are usually not good for } \\
& \text { internet connection / Outside noise considerations) }\end{array}$ \\
\hline \multicolumn{2}{|l|}{ COURSE CONCEPTS } \\
\hline Disciplinary anchors & - $\quad$ Core concepts to be conveyed \\
\hline $\begin{array}{l}\text { Division of tasks and delivery of } \\
\text { lectures (who and when) }\end{array}$ & $\begin{array}{l}\text { - } \quad \text { Write up of Course Masterplan with plenty of time for } \\
\text { discussion between partners (2-3 months in advance) }\end{array}$ \\
\hline \multicolumn{2}{|l|}{ REFLECTION } \\
\hline $\begin{array}{l}\text { When, and at what stages of } \\
\text { semester }\end{array}$ & $\begin{array}{ll}\text { - } & \text { E.g. Feedback at start of module as to students hopes / } \\
\text { expectations / ascertaining digital literacy skills } \\
\text { - } \quad \text { Interim reflection, if planned } \\
\text { - } & \text { At close of module, ascertain if expectations were met and } \\
\text { how students viewed module compared to other T\&L } \\
\text { formats. Encourage open-ended feedback. }\end{array}$ \\
\hline $\begin{array}{l}\text { Form and format } \\
\text { (individual and / or group } \\
\text { reflection) }\end{array}$ & $\begin{array}{ll}- & \text { Qualitative and or quantitative research methodology } \\
\text { - } & \text { Anonymous individual questionnaires } \\
\text { - } & \text { In-class or online } \\
\text { - } & \text { Include virtual, online, and / or in-class feedback session(s) }\end{array}$ \\
\hline
\end{tabular}

